\title{
Calculating Size of Pump-Hydro Combined Energy Storage System in Wind-Diesel Systems Based on PHCES Dynamic Model
}

\author{
Su Wang, Kwoklun Lo, Jianfeng Lu \\ Department of Electronic and Electrical Engineering, University of Strathclyde, Glasgow, United Kingdom \\ Email: s.wang.100@strath.ac.uk
}

How to cite this paper: Wang, S., Lo, K.L. and Lu, J.F. (2017) Calculating Size of Pump-Hydro Combined Energy Storage System in Wind-Diesel Systems Based on PHCES Dynamic Model. Energy and Power Engineering, 9, 224-231.

https://doi.org/10.4236/epe.2017.94B027

Received: February 19, 2017

Accepted: March 30, 2017

Published: April 6, 2017

\begin{abstract}
This paper will propose an approach to calculate and evaluate the reserve capacity and energy size of Pumping-Hydro Combined Energy Storage (PHCES) when wind power is integrated to power grid while considering the scheme of generation capacity allocation and operation of PHCES. This approach will use Monte Carlo Method to simulate large amount of samples to obtain the minimum value of capacity and energy size that could satisfy the requirement of system reliability. Finally this approach will apply in a RBTS system to assess the project feasibility.
\end{abstract}

\section{Keywords}

Wind Power, PHCES, Operation of PHCES, Reliability

\section{Introduction}

With the increasing attention of environment protection and depletion of fossil fuel sources, the increasing advancement of renewable energy sources is indispensable [1]. Among these renewable energy sources, wind power has certainly progress in the past two decades, and is expected to be a significant part of the electric power consumption to reduce the reliance on fossil fuels in many places [2].

Wind power has some adverse effect on power system owing to wind output is uncertain and variable, In addition, the electric energy is often supplied by diesel generators that can only operate in a fixed range in many grids. Therefore, there is a potential reliability issue when integrated wind power in to grid, which is the imbalance power between local demand and power generation [3]. To solve this problem, some auxiliary units can be utilized such as low-load diesel generator, 
flywheel dump load, PHCES and some other energy storage systems [5] [6]. In addition, appropriate reliability evaluation is highly required in power system designing and planning in order to make the system operates under successive good condition. Also analytical methods and simulation techniques are utilized to determine the sufficient generating capacity [4].

In this paper, a simulation technique to size a PHCES for power system with wind farm based on PHCES dynamic model and scheme of generation capacity allocation is presented. It could provide beneficial information for wind farm owners and power system designers to evaluate the optimal size of PHCES. In addition, Monte Carlo simulation was used to determine the reasonable capacity power and energy size of PHCES and system reliability, because that this method do not depend on truly random numbers and it is suitable for evaluate complex systems [7] [8]. Section 2 describes the component models of power system with wind farms and PHCES dynamic model. is approach is applied to the RBTS and the simulation PHCES sizing is presented in Section 3. Finally, a conclusion is summarized in Section 4.

\section{Reliability Evaluation Model Based On Monte-Carlo Algorithm}

\subsection{Wind Speed and Wind Farm Output Model}

In this paper, Weibull probability density function has been utilized to predict the value of wind speed every hour $v_{\text {wind }}$. This method has been explained in [9].

The power output of wind turbine forcefully not only depends on wind speed, but also the performance characteristics of the turbine. The power output curve of the wind farm can be calculated by Equation (1).

$$
P_{\text {wind }}=\left\{\begin{array}{lc}
0 & v_{\text {wind }} \leq v_{c i} \\
\left(A-B \times v_{\text {wind }}+C \times v_{\text {wind }}^{2}\right) \times P_{\text {rate }} & v_{c i}<v_{\text {wind }} \leq v_{r} \\
P_{\text {rate }} & v_{r}<v_{\text {wind }} \leq v_{c o} \\
0 & v_{\text {wind }}>v_{c o}
\end{array}\right.
$$

where $v_{c i}, v_{c r} v_{c o}$ : designed cut-in speed, rate speed and cut-out speed of wind turbine $(\mathrm{m} / \mathrm{s})$

$\nu_{\text {wind }}:$ wind speed $n(\mathrm{~m} / \mathrm{s})$

$P_{\text {rate }}:$ rated power output of wind turbine (MW)

The constants of $A, B, C$ can be calculated based on the equation in [14].

Also the forced outage rate (FOR) of wind and conventional generators will be taken in to account. FOR of units indicates the unavailability of the system that is the basic parameter of non-sequential simulation algorithm measuring the system status by sampling, and the wind turbine will meet an average of 170 hours downtime and 1.5 times failures per year per turbine.

\subsection{Load and Conventional Generating System Model}

Load profile is difficult to predict because that it will influence by many factors, 
such as customer types, temperature and seasons. Hourly peak power consumption load model is most primitive and extensively adopted, and is established by documenting the load peak power in a set time [9]. Four elements are need to simulate a load profile which are hourly peak load, daily peak load, weekly peak load and annual peak load.

Conventional generating system model will consider the scheme of generation capacity allocation which is that conventional generators will provide constant percentage of load demand, and the remaining load demand will supplied by wind power and PHCES, and the total real output of conventional generators $P_{\text {realcon }}$ could be evaluated by Equation (2). One thing to note here is that when $P_{L}(t)$ is smaller than $P_{\min }$, conventional generator will generate the minimum output and surplus energy will be stored or abandoned.

$$
P_{\text {realCON }}(t)=\left\{\begin{array}{l}
P_{\mathrm{CON}}(t)\left(\eta_{\mathrm{CON}} \times P_{L}(t) \geq P_{\mathrm{CON}}(t)\right) \\
\eta_{\mathrm{CON}} \times P_{L}(t)\left(P_{\min }<\eta_{\mathrm{CON}} \times P_{L}(t)<P_{\mathrm{CON}}(t)\right) \\
P_{\text {min }}(t)\left(\eta_{\mathrm{CON}} \times P_{L}(t)<P_{\min }\right)
\end{array}\right.
$$

where $P_{\mathrm{CON}}(t), P_{L}(t)$ : the available maximum power output of conventional generators and load demand at time $t(\mathrm{MW})$.

$\eta_{\mathrm{CON}}$ : the constant percentage of load demand that conventional generators should applied.

$P_{\min }:$ the minimum output of conventional generators (MW).

\subsection{PHCES Model}

PHCES is addressed to compensate the generation output in order to balance the total generation and total demand in the system, when the output of conventional generators and wind farms do not match the total requirement of the loads. There are 11 conditions of PHCES operation, so that the dynamic PHCES model could be modified and Table 1 shows how to calculate the output $P_{\mathrm{PHCES}}$ and stored energy $E_{\text {PHCES }}$ of PHCES in these conditions clearly. $P_{r \text { PHCES }}$ is the rated power of PHCES, the energy $E_{\text {PHCES }}(t-1)$ is the energy store by PHCES in time $t-1$, and $\eta_{P S}$ is the efficiency of PHCES generators.

The outage power $P_{\text {dif }}(\mathrm{MW})$ is load demand and generating power which include conventional generators output and wind farm, and it will influence the operation of PHCES and can be shown clearly in Equation (3). Positive value of outage power means the power output that PHCES need discharge the system, instead, need charge. In addition, the outage energy $E_{\text {dif }}$ that PHCES should discharge or store in each cycle can be calculated by the consecutive positive or negative $P_{\text {dif }}$.

$$
P_{\text {dif }}=P_{L}(t)-\left(P_{\text {realcon }}(t)+P_{\text {wind }}(t)\right)
$$

\subsection{Reliability Model}

Effective load carrying capacity (ELCC) is a kind of reliability index and is used to evaluate the value of the capacity of added renewable and traditional power plant. Loss of load expectation (LOLE) is the most common used index utilized 
Table 1. The operation condition of PHCES.

\begin{tabular}{|c|c|c|c|}
\hline Operation Condition & $\begin{array}{l}\text { Power output (MW) } \\
\qquad P_{\text {PHCES }}(t)\end{array}$ & $\begin{array}{l}\text { Stored Energy } \\
\qquad(\mathrm{MWh}) \\
E_{\text {PHCES }}(t)\end{array}$ & $\begin{array}{c}\text { Loss of Load } \\
\text { Expectation } \\
\text { LOLE }(t)\end{array}$ \\
\hline $\begin{array}{c}E_{\text {PHCES }}(t-1)=0 \\
\quad P_{\text {dif }}(t)>0\end{array}$ & 0 & 0 & 1 \\
\hline $\begin{array}{c}P_{r \text { PHCES }}>E_{\text {PHCES }}(t-1)>0, \\
P_{\text {dif }}(t)>P_{r \text { PHCES }}\end{array}$ & $E_{\text {PHCES }}(t-1)$ & 0 & 1 \\
\hline $\begin{array}{c}E_{\text {PHCES }}(t-1) \geq P_{r \text { PHCES }}, \\
P_{\text {dif }}(t)>P_{r \text { PHCES }}\end{array}$ & $P_{\text {rPHCES }}$ & $E_{\text {PHCES }}(t-1)-P_{\text {rPHCES }}$ & 1 \\
\hline $\begin{array}{c}E_{\text {PHCES }}(t-1) \geq P_{r \mathrm{PHCES}}, \\
0<P_{\mathrm{dif}}(t) \leq P_{r \mathrm{PHCES}}\end{array}$ & $P_{\mathrm{dif}}(t)$ & $E_{\text {PHCES }}(t-1)-P_{\text {dif }}(t)$ & 0 \\
\hline $\begin{array}{c}E_{\text {PHCES }}(t-1)<P_{r \text { PHCES }}, \\
0<P_{\text {dif }}(t) \leq P_{r \text { PHCES }}\end{array}$ & $E_{\text {PHCES }}(t-1)$ & 0 & 1 \\
\hline$E_{\text {PHCES }}(t-1)=E_{\max }, \quad P_{\text {dif }}(t)<0$ & 0 & $E_{\max }$ & \\
\hline $\begin{array}{c}E_{\max }-E_{\text {PHCES }}(t-1)>\eta_{P S} \times P_{r \text { PHCES }} \\
P_{\text {dif }}(t) \leq-P_{r \text { PHCES }}\end{array}$ & $-P_{\text {rPHCES }}$ & $E_{\text {PHCES }}(t-1)+\eta_{P S} \times P_{r \text { PHCES }}$ & 0 \\
\hline $\begin{array}{c}E_{\max }-E_{\text {PHCES }}(t-1) \leq \eta_{P S} \times P_{\text {rPHCES }}, \\
P_{\text {dif }}(t) \leq-P_{r \text { PHCES }}\end{array}$ & $\left(-E_{\max }+E_{\text {phes }}(t-1)\right) / \eta_{P S}$ & $E_{\max }$ & 0 \\
\hline $\begin{array}{c}E_{\max }-E_{\text {PHCES }}(t-1)>\eta_{P S} \times P_{r P H C E S} \\
0>P_{\text {dif }}(t)>-P_{r \text { PHCES }}\end{array}$ & $P_{\mathrm{dif}}(t)$ & $E_{\text {PHCES }}(t-1)-\eta_{P S} \times P_{\text {dif }}(t)$ & 0 \\
\hline $\begin{array}{c}E_{\max }-E_{\text {PHCES }}(t-1) \leq \eta_{P S} \times P_{r P \text { PHES }} \\
0>P_{\text {dif }}(t)>-P_{r \text { r HCES }}\end{array}$ & $\left(-E_{\max }+E_{\text {phes }}(t-1)\right) / \eta_{P S}$ & $E_{\text {max }}$ & 0 \\
\hline$P_{\text {dif }}(t)=0$ & 0 & $E_{\text {PHCES }}(t-1)$ & 0 \\
\hline
\end{tabular}

to evaluate ELCC, which means the risk standard of the additional power plant, and in this paper, LOLE is considered as the reliability index and can be evaluated by Equation (4).

$$
\text { LOLE }=\sum_{t=1}^{N} p\left(P_{L}(t)<P_{\text {realCON }}(t)+P_{\text {wind }}(t)+P_{\text {PHCES }}(t)\right)
$$

The aim of this paper is to searching the reasonable power capacity and energy size amount of PHCES which cooperated with wind power could let the result of Monte-Carlo simulation with LOLE value similar to conventional system. Though Equations (5) and (6) the power capacity and energy size could be simulated.

$$
\begin{gathered}
P_{r \text { PHCES }}=\sum_{i=1}^{N}\left(P_{\text {difmax }}(i)\right) / N \\
E_{\max }=\sum_{i=1}^{N}\left(E_{\text {difmax }}(i)\right) / N
\end{gathered}
$$

where: $P_{\text {difmax }}(i)(\mathrm{MW})$ and $E_{\text {difmax }}(i)(\mathrm{WMh})$ are the maximum value of $P_{\text {dif }}$ 
and $E_{\text {dif }}$ in ith simulation of Monte-Carlo Method.

$N$ is the total number of samples for Monte-Carlo (in this paper, $N=10000$ ).

There are five steps to evaluate the reliability index of test system:

1) Utilizing annual peak load demand and certain load variation pattern to predict load model $P_{L}$ in one year.

2) Using capacity and reliability data to build conventional generator output $P_{\text {newCON }}$ which based on the selected scheme of generation capacity allocation.

3) Simulating the output of wind farm $P_{\text {wind }}$.

4) Calculating $P_{r \text { PHCES }}$ and $E_{\max }$ of PHCES by using Monte-Carlo Method.

5) Evaluating LOLE of test system by comparing $P_{\text {newCON }}+P_{\text {wind }}+P_{\text {PHCES }}$ and $P_{L}$.

\section{Results and Discussion}

In this paper, the load model data is modified based on the IEEE-RTS which is developed by the IEEE subcommittee on the Application of Probability Methods [10]. Figure 1 shows an annual load demand $P_{L}$ curve which peak load is 185 MW.

The total capacity of generating units is $240 \mathrm{MW}$ which base on modified RBTS test system. The capacity of generating units and reliability data of modified RBTS test system has been shown in Table 2. Figure 2 shows one of the simulated availabe maximum output of conventional output $P_{\mathrm{CON}}(t)$.

The wind penetration level is the ratio of the installed wind generation capacity to the total installed system generation capacity, and assumes wind power penetration level is $20 \%$ in this case study. As previously mentioned, the total installed power capacity of conventional generators is $240 \mathrm{MW}$, and the total installed power capacity of wind farm is $48 \mathrm{MW}$. Besides that, the constant percentage of load demand that conventional generators should applied set to $90 \%$. So that the real power output of conventional and the power output of wind farm could be simulated in a year. The curve of one year would be too dense, so this case study will show the curve in 100 hours. In Figure 3, one simulation sample of predict conventional output, wind output and typical load power curve has been shown in 100 hours.

Table 2. Generating unit capacity and reliability data.

\begin{tabular}{cccc}
\hline Unit size (MW) & No. of units & $\begin{array}{c}\text { Failure times per year } \\
\text { (occ/year) }\end{array}$ & $\begin{array}{c}\text { average downtime } \\
\text { (hours/year) }\end{array}$ \\
\hline 5 & 2 & 2 & 45 \\
10 & 1 & 4 & 45 \\
20 & 4 & 2.4 & 55 \\
20 & 1 & 5 & 45 \\
40 & 1 & 3 & 60 \\
40 & 2 & 6 & 45 \\
\hline
\end{tabular}


Figure 4 shows the curves of load demand and available generating power capacity (includes wind power and conventional power). From this figure and simulation results, if load curve higher than the available generating power curve, it means that PHCES need runs at hydro situation and discharge the system. Instead, PHCES will run at pump situation and charge the system. According to the matching relationship between the output of the system and load demand, the power that PHCES should balance could obtained (see Figure 5).

After 10,000 sampling, the reasonable capacity and energy size amount of PHCES can be evaluated. In this case, $P_{\text {rPHCES }}$ is $25 \mathrm{MW}$, and $E_{\max }$ is 168 MWh.

The simulation results of reliability indices for conventional generation power system, wind-conventional generation power system and wind-conventional generation power system with PHCES are 1.0717, 19.3847 and 1.0346. Hence, for this system, the PHCES which minimum capacity data are $25 \mathrm{MW}$ and 168 MWh should be installed to increase system reliability and satisfy the requiement of the scheme of generation capacity allocation.

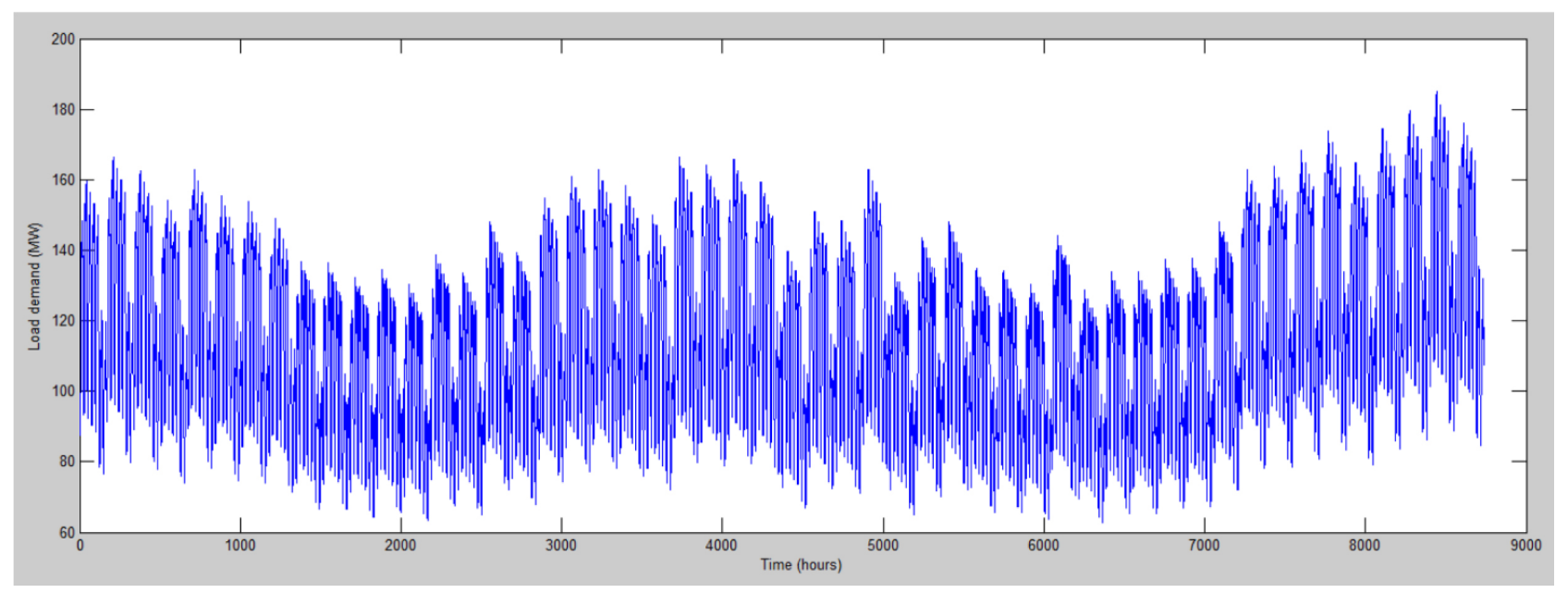

Figure 1. The load demand curve.

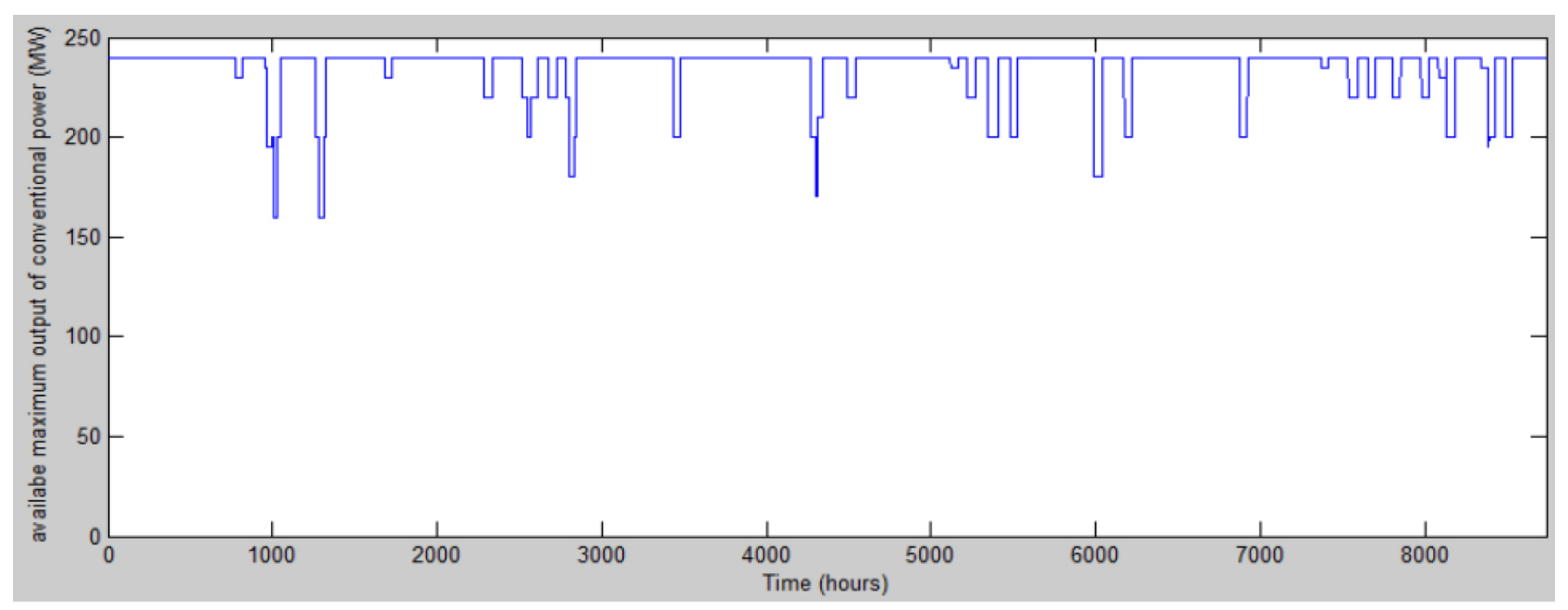

Figure 2. The available maximum output of conventional output. 


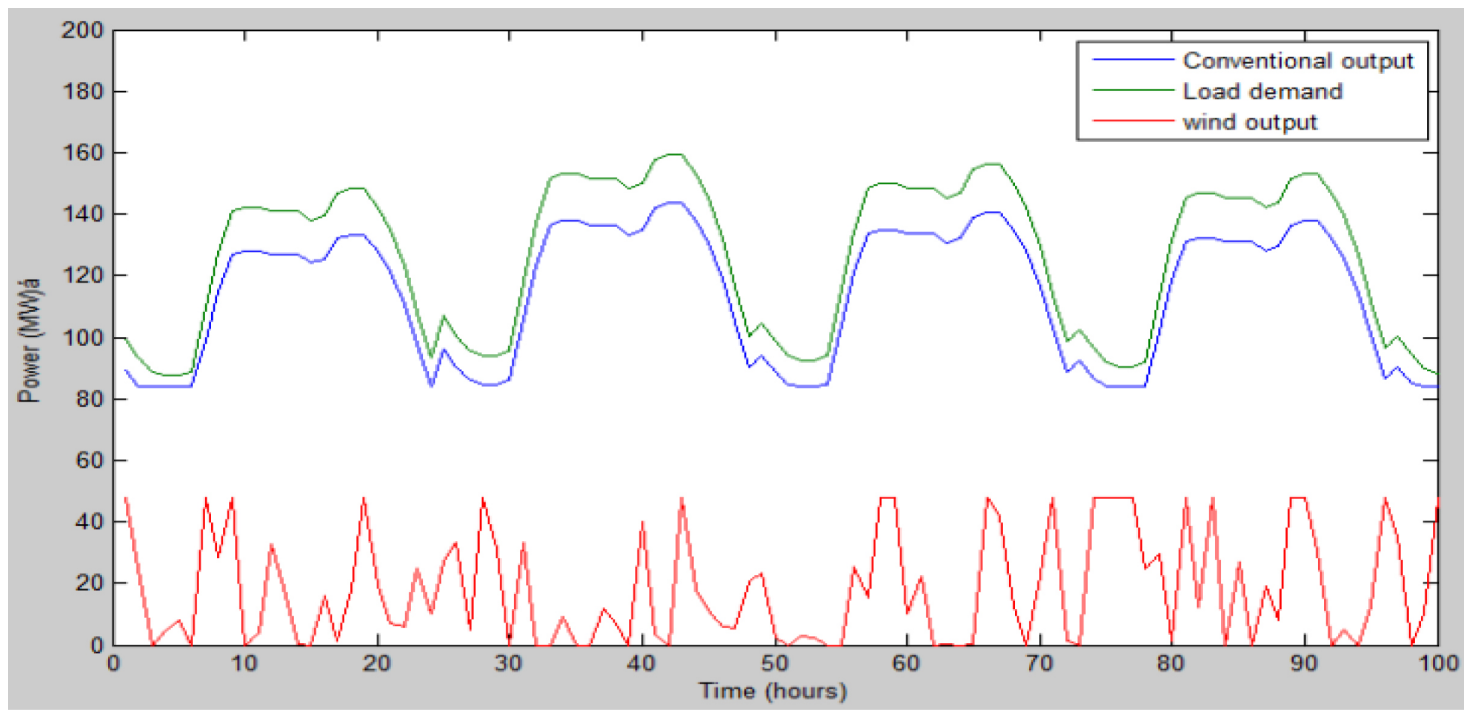

Figure 3. Wind farm output curve, conventional output curve and load curve.

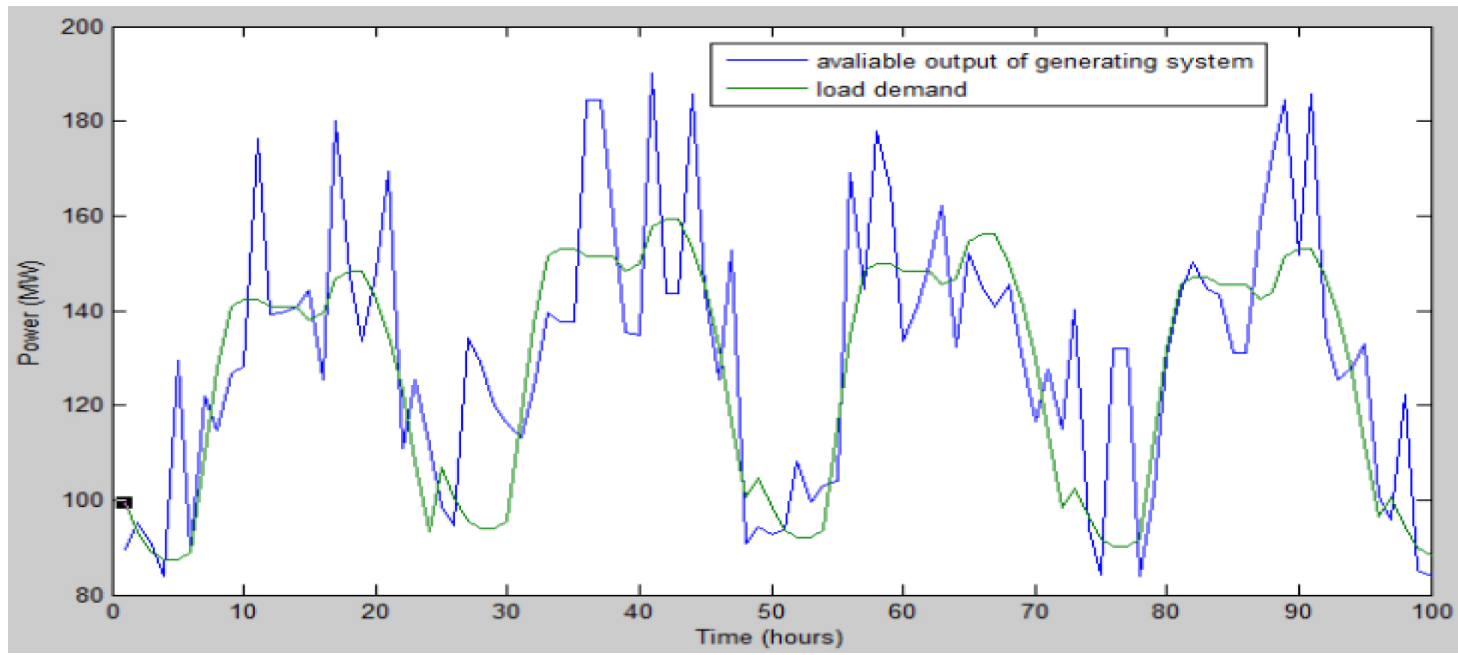

Figure 4. Curve of load demand and available generating power capacity.

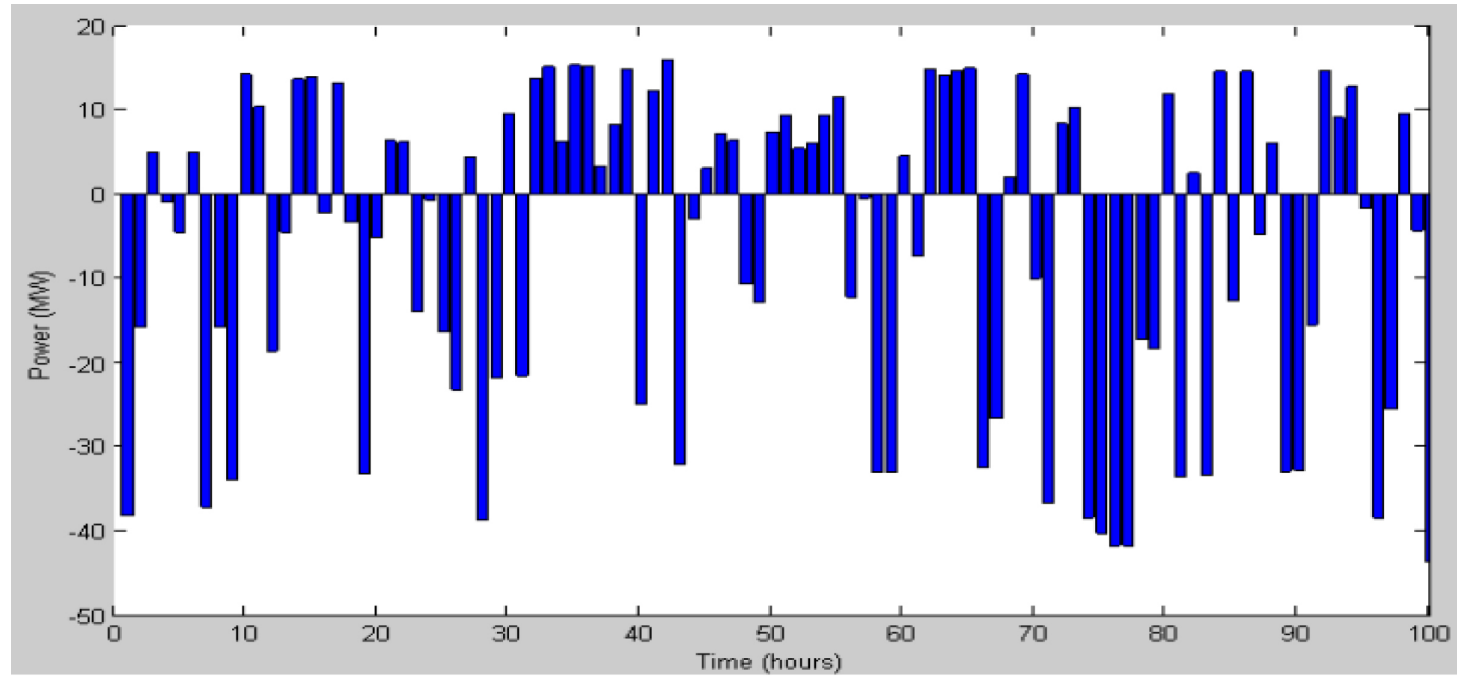

Figure 5. Curve of required capacity changes of PHCES. 


\section{Conclusion and Future Work}

This paper presents a way to evaluate the capacity of PHCES when wind power is integrated to power grid while considering the scheme of generation capacity allocation and operation of PHCES. It shows that PHCES with wind power integration could increase the reliability of generating system though balance the output of wind farm. The methodology is based on Monte Carlo method that is used to calculate the reasonable capacity and energy size of PHCES and calculate the system reliability.

Future work will focus on reliability cost and worth analysis to find the optimal capacity and energy size of PHCES. The approach proposed in this paper could calculate the operation of PHCES which contribute to evaluate the worth of PCHES.

\section{References}

[1] (2009) Department of Energy and Climate Change.UK Renewable Energy Strategy, London.

[2] Saidur,R., et al. (2010)Areview on Global Wind Energy Policy. Renewable and Sustainable Energy Reviews, 14, 1744-1762.https://doi.org/10.1016/j.rser.2010.03.007

[3] Chowdhury, A.A., Zhang, Y. andAl,E.(2009) Practice of Large Wind Generation Interconnection Study in CAISO.IEEE PES 2009 General Meeting.

[4] Allan,R. (1994) Power System ReliabilityAssessment-A Conceptual and Historical Review. Reliability Engineering \& System Safety, 46, 3-13. https://doi.org/10.1016/0951-8320(94)90043-4

[5] Baring-Gould,I. andDabo,M.(2009) Technology, Performance, and Market Report of Wind Diesel Applications for Remote and Island Communities. National Renewable Energy Laboratory (NREL).

[6] (2009) Impact of increased DFIG Wind Penetration on Power System and Markets. Power System Engineering Research Center.

[7] Papaefthymiou, G. and Klockl, B. (2008) MCMC for Wind Power Simulation IEEE trans. Energy Convers., 234-240

[8] Hegazy, Y.G., Salama, M.M.A. and Chikhani A.Y.(2003) Adequacy Assessment of Distributed Generation Systems Using Monte Carlo Simulation, IEEE Trans. Power System, 48-52.https://doi.org/10.1109/TPWRS.2002.807044

[9] Wang, S., et al.(2016) An Approach to Calculate the Capacity of Pump-Hydro Combined Energy Storage with Wind Power Integration. World Journal of Engineering and Technology, 43-49

[10] Billinton, R. and Allan R.N. (1996) Reliability Evaluation of Enginerring Systems.

[11] Billinton, R. (1989) A reliability Test System for Educational Purposes-Basic Data. Power Systems, IEEE Transactions on, 1238-1244. 
Submit or recommend next manuscript to SCIRP and we will provide best service for you:

Accepting pre-submission inquiries through Email, Facebook, LinkedIn, Twitter, etc. A wide selection of journals (inclusive of 9 subjects, more than 200 journals)

Providing 24-hour high-quality service

User-friendly online submission system

Fair and swift peer-review system

Efficient typesetting and proofreading procedure

Display of the result of downloads and visits, as well as the number of cited articles Maximum dissemination of your research work

Submit your manuscript at: http://papersubmission.scirp.org/

Or contact epe@scirp.org 